\begin{tabular}{|c|c|}
\hline Title & U Itraviolet-photon exposure stimulates negative current conductivity in amorphous ice below $50 \mathrm{~K}$ \\
\hline Author(s) & Watanabe, N.; Sameera, W. M. C.; Hidaka, H.; Miy azaki, A .; Kouchi, A. \\
\hline Citation & $\begin{array}{l}\text { Chemical physics letters, 737, } 136820 \\
\text { https://doi.org/10.1016/.cplett.2019.136820 }\end{array}$ \\
\hline Issue Date & 2019-12-16 \\
\hline DOC URL & http:/hdl.handle.net/2115/83556 \\
\hline Rights & $\begin{array}{l}\text { @2019. This manuscript version is made available under the CC-BY-NC-ND } 4.0 \text { license } \\
\text { http://creativecommons.org/icenses/by-nc-nd/4.0/ }\end{array}$ \\
\hline Rights(URL) & https://creativecommons.org/icenses/by-nc-nd/4.0/ \\
\hline Type & article (author version) \\
\hline File Information & Chemical physics letters_737_136820.pdf \\
\hline
\end{tabular}

Instructions for use 


\title{
Ultraviolet-photon exposure stimulates negative current conductivity in amorphous ice below $50 \mathrm{~K}$
}

\author{
N. Watanabe*, W.M.C. Sameera, H. Hidaka, A. Miyazaki, A. Kouchi \\ Institute of Low Temperature Science, Hokkaido University, N19-W8, Kita-ku, Sapporo, \\ Hokkaido 060-0819, Japan \\ * Author to whom correspondence should be addressed: watanabe@lowtem.hokudai.ac.jp
}

\begin{abstract}
Water ice is known to carry positive charge via transfer of excess protons through a hydrogen-bonded system. In contrast, constant negative charge conductivity in ice has neither been confirmed experimentally nor theoretically. Here, we report that ultraviolet-photon irradiation stimulates negative current conductivity in amorphous ice at temperatures below $50 \mathrm{~K}$, where hitherto known proton transfer from the surface through the bulk ice is inhibited. Quantum chemical calculations imply that the negative current conductivity results from almost barrier-less proton-hole transfer processes that neither requires intrinsic defects, doped species, nor reorientation of $\mathrm{H}_{2} \mathrm{O}$ molecules in ice.
\end{abstract}




\section{Introduction}

Water ice is well known to deliver positive current similar to a "p-type" semiconductor via the proton transfer of excess hydronium ions [1]. Because of its importance in various chemical and biological processes [1-3], proton transfer in both liquid water [4-6] and ice [7-9] has been extensively studied. Although the detailed mechanism, especially at low temperatures $[7,10]$, is still under debate, the positive current conductivity in ice can be well described by the relay of proton transfer, the so-called "Grotthuss mechanism" [1]. For the negative current conductivity, the concept of "a proton-hole transfer (PHT)" was proposed about 100 years ago [11]. The PHT is the relay of proton-abstraction of $\mathrm{OH}^{-}$ion from neighboring $\mathrm{H}_{2} \mathrm{O}$, and therefore was considered as a "mirror image" concept of the Grotthuss mechanism. However, to date the efficient negative current conductivity has not been found for both liquid water [12] and ice $[13,14]$. In water, the mechanism of $\mathrm{OH}^{-}$migration was found to differ from the PHT concept [15] and recent years, migration of $\mathrm{OH}^{-}$in water was reported to be much less effective than the proton transfer [12]. In water, $\mathrm{H}^{+}$exists as single complex of tricoordinate $\mathrm{H}_{3} \mathrm{O}^{+}\left(\mathrm{H}_{2} \mathrm{O}\right)_{3}$, and the proton transfer is conducted by the re-formation of this tricoordinate form via intermediate $\mathrm{H}_{5} \mathrm{O}_{2}{ }^{+}$(i.e. the Grotthuss mechanism). In contrast, $\mathrm{OH}^{-}$in water exists to alternate between two configurations, which are a hypercoordinated form with four acceptor $\mathrm{H}$-bonds to neighbor water molecules and a nearly tetrahedral form with three acceptor H-bonds [15]. Since the proton abstraction only occurs in the tetrahedral form, transformation from the hypercoordinated form to the tetrahedral form is necessary before the proton abstraction [15]. Thus, migration of $\mathrm{OH}^{-}$in water is not the mirror image of the Grotthuss mechanism. This difference may lead to the low efficiency of the $\mathrm{OH}^{-}$relay in aqueous medium. Furthermore, a recent ab-initio molecular dynamics simulation have shown that the multiple proton jumps that enhance the efficiency of the proton relay, namely the concerted proton transfers, are strongly suppressed in the $\mathrm{OH}^{-}$system due to the higher activation barrier than that in $\mathrm{H}_{3} \mathrm{O}^{+}$, [12]. This also contributes to low efficiency of the proton abstraction in the $\mathrm{OH}^{-}$ in aqueous medium. Eventually, suppression of PHT in water would originate from the hypercoordination form, which is shaped by four $\mathrm{H}_{2} \mathrm{O}$ molecules sterically surrounding $\mathrm{OH}^{-}$.

In ice, the hypercoordination complex may not be formed due to the limited motion of $\mathrm{H}_{2} \mathrm{O}$ molecules unlike in liquid phase. However, no theoretical studies about $\mathrm{OH}^{-}$migration in ice have been reported to date. Thus, the PHT phenomenon in ice still remains unexplored, although it is a fundamental electrochemical property of ice. In 
experiments, negative current conductivity in ice has been examined by electron bombardment of ice or using base-doped ice, which results in $\mathrm{OH}^{-}$ions in bulk ice. For the doped ice experiment, a small negative charge delivery was observed above $140 \mathrm{~K}$, and was reported to be the result of $\mathrm{OH}^{-}$Brownian migration rather than the PHT [14]. For the electron bombardment of ice, although a transient negative current probably due to the transport of solvated electrons was observed, and it immediately diminished below $50 \mathrm{~K}$ [16]. In addition, the negative current conductivity has never been examined when $\mathrm{OH}^{-}$ions on the surfaces of ice. The PHT at the surface may control the negative current conductivity as the first step of PHT relay in bulk. This phenomenon is also relevant to chemistry of ice dust surfaces in space and planetary atmosphere, where it is important to know whether the negative charge on $\mathrm{OH}$ can be localized on the surface [17].

Here, we report that ultraviolet-photon (UV) irradiation stimulates negative current conductivity in amorphous ice below $50 \mathrm{~K}$, where positive current by proton transfer from the surface to the bulk ice is significantly suppressed [8]. We found that the negative constant current can be controlled by UV irradiation. No temperature dependence or isotope effect was observed in the range of 10-50 K. Quantum chemical calculations suggest that the negative current results from the PHT in ice, triggered by the surface $\mathrm{OH}^{-}$ions, which are created by photodissociation of $\mathrm{H}_{2} \mathrm{O}$ and subsequent electron attachment onto $\mathrm{OH}$ radical at the surface. The computed barrier of the proton abstraction by $\mathrm{OH}^{-}$is very low, in accordance with the experimentally observed temperature independence of conductivity. This process requires neither intrinsic defects nor reorientation of the $\mathrm{H}_{2} \mathrm{O}$ molecules in bulk ice, in contrast to the well-known positive current conductivity by the transfer of excess protons. The present paper strongly suggests the occurrence of the PHT in ice and may lead to a new aspect of the electrochemical nature of ice, which has been commonly considered as a positive current semiconductor.

\section{Measurements of negative current conductivity on ice}

In an ultra-high vacuum chamber, water ice samples with $\sim 40$ or 120 monolayers (MLs) were prepared at $10 \mathrm{~K}$ in an amorphous form by backfill deposition over a nickel (Ni) substrate plated on a sapphire disk. The current through the amorphous ice was measured at the Ni substrate. The samples were exposed to UV photons from a deuterium $\left(\mathrm{D}_{2}\right)$ lamp. At the top of the $\mathrm{D}_{2}$ lamp, a cylindrical stainless-steel metal guide was mounted to enables UV photons to illuminate the sample 
area only. The UV flux at the substrate without ices was approximately $2.5 \times 10^{13} \mathrm{~cm}^{-2} \mathrm{~s}^{-1}$. During the lamp operation, photoelectrons were created on the inner wall of the metal guide. By applying $-60 \mathrm{~V}$ at the guide, photoelectrons were pushed towards the sample surface as shown in Fig. 1(a). When the UV photons reach the Ni surface, photoelectrons should be also emitted from the Ni substrate and cause positive current. When the guide was set to $-60 \mathrm{~V}$, the measured current at the substrate without ice was approximately $+0.7 \mu \mathrm{A}$ upon UV irradiation. This indicates that the photoelectrons emitted from the Ni substrate were dominant over those coming in from the guide. When ices were exposed to UV, we found a negative current flow at the substrate even below $50 \mathrm{~K}$. As shown in Fig. 1(b), the negative current sharply responded to the application and removal of UV irradiation. The peak currents were almost temperature independent within a $10 \%$ variation between 10 and $50 \mathrm{~K}$. The peak current through 120 -ML ice was reduced by $10 \%$ of that for $40 \mathrm{ML}$. After irradiation for $120 \mathrm{~min}$, the current through $40-\mathrm{ML}$ ice decreased by approximately $20 \%$. Although it is not possible to determine the contribution of positive current by photoelectron emission from the substrate, the obtained result indicates that photoelectron from the substrate is largely suppressed by ice coverage and exceeded by the UV-stimulated negative current through ice in total. To clarify the origin of negative current, effects of UV photolysis of ice and photoelectron landed on the ice surface were investigated as follows.

In the second experiment, to evaluate how each process affects the negative current conductivity, we modified the setup so that the ice sample can be exposed to UV or electrons independently, as shown in Fig. 1(c). Installing a glass capillary plate on the top of a cylindrical guide can allow only UV emission by blocking the photoelectrons created within the guide while an electron gun is mounted facing the substrate. Using this setup, the ice was exposed to electrons with and without UV. When ice was exposed to electrons only, the negative current immediately dropped, showing a peak when the electron gun was turned on, as previously reported [16]. However, when UV was supplied during the continuous electron exposure, a significant negative current appeared (see Fig. 1(d)). The case in which only UV irradiation was applied is described later. These results clearly indicate that the negative constant current is generated by UV irradiation with the supply of electrons to the ice surface. UV photons from a conventional deuterium lamp cover a Lyman $-\alpha$ and -band of hydrogen and thus can photolyse $\mathrm{H}_{2} \mathrm{O}$ via several pathways to produce $\mathrm{OH}+\mathrm{H}, \mathrm{O}+\mathrm{H}_{2}, \mathrm{O}+2 \mathrm{H}$, or $\mathrm{H}_{3} \mathrm{O}^{+}+$ $\mathrm{OH}+\left(\mathrm{D}\right.$ defect $+\mathrm{e}^{-}+$vacancy $)$from $2 \mathrm{H}_{2} \mathrm{O}$ [18]. Considering that the pathway producing $\mathrm{OH}+\mathrm{H}$ is the main branching path in the present range of $\mathrm{UV}$ photon energy [19], $\mathrm{OH}$ radicals produced at the surface should play an important role in carrying the 
negative current. Because the $\mathrm{OH}$ radical has a higher electron affinity of $\sim 1.8 \mathrm{eV}$ than those of the other photofragments [20], it would readily convert to $\mathrm{OH}^{-}$ions by capturing electrons that landed on the surface, and this $\mathrm{OH}^{-}$would trigger the negative current. The energy of electrons from the electron gun can dissociate $\mathrm{H}_{2} \mathrm{O}$. However, it is known that the ice surface can be immediately charged up to the voltage of electron energy when it is exposed to electron beam [21] and thus the electron current and energy would drop significantly at the ice surface. Nevertheless, in Fig. 1(d), the sharp transient peak at the timing of electron-gun on without UV irradiation might be due to the $\mathrm{OH}$ production by electron bombardment until getting charged up. Considering the experimental results that the constant negative current flows through ice bulk even at low temperatures when $\mathrm{OH}^{-}$is created on the surface, we deduce that the negative current conductivity originates from the PHT through ice triggered by $\mathrm{OH}^{-}$at the surface rather than $\mathrm{OH}^{-}$Brownian motion or solvent electrons. To further investigate the possibility of PHT in ice, we performed quantum chemical calculations.

\section{Computational studies}

We used the two-layer ONIOM method [22,23] as implemented in the Gaussian16 program [24] to study an $\mathrm{OH}$ anion on ice. In this method, the electronically important part of the molecular system is described by an accurate quantum mechanical (QM) method, while the remaining part of the system is described by a computationally efficient molecular mechanics (MM) method. As the reaction center is calculated at an accurate QM method, energies of the stationary points of potential energy surfaces and reaction barriers can be calculated more accurately. In our two-layer ONIOM calculations, the wB97X-D [25] functional and the def2-TZVP [26] basis sets were employed for the QM region. The AMBER [27] force field was used for the MM region. Vibrational frequency calculations were performed to confirm that the optimized structure is a local minima (i.e., no imaginary frequency) or a transition state (i.e., one imaginary frequency), and to calculate the zero-point energy. Potential energy of the optimized stationary points were calculated as ONIOM(QM:QM) single-point calculations, where the domain-based local pair natural orbital couple (DLPNO)-CCSD(T) method, cc/pVTZ basis sets and cc-pVTZ/C auxiliary basis sets in the ORCA 4.0 program [28] were used for the high-level, while the wB97X-D/def2TZVP method was used for the low-level. We have used the crystalline hexagonal water ice $\left(\mathrm{I}_{\mathrm{h}}\right)$ and amorphous ice models of Andersson et al. [29] as the starting structures to make ice cluster models. Our ice cluster models of ice $I_{h}$ or amorphous ice 
consist of $162 \mathrm{H}_{2} \mathrm{O}$ molecules, where $48 \mathrm{H}_{2} \mathrm{O}$ molecules are in the QM region, and 114 $\mathrm{H}_{2} \mathrm{O}$ molecules are in the MM region. To save computational cost and to avoid structure deformations, $\mathrm{H}_{2} \mathrm{O}$ molecules in the bottom and at the sides were frozen upon structure optimizations.

First, we have optimized an $\mathrm{OH}$ radical on a crystalline hexagonal ice $\left(\mathrm{I}_{\mathrm{h}}\right)$ or amorphous ice (Fig 2), where OH radical is stable on ice (i.e. a local minima). Although the results for amorphous ice are essentially the same as those for $I_{h}$, descriptions using the $\mathrm{I}_{\mathrm{h}}$ results can help clearly to illustrate what happens in ice. We produced $\mathrm{OH}^{-}$ion on $\mathrm{I}_{\mathrm{h}}$ by introducing an electron to the $\mathrm{OH}$ radical local minimum, which was the starting point for an ab-initio molecular dynamic simulation using the atom-centered density matrix propagation (ADMP) method [30], employing the wB97XD/6-31G(d)[31] level of theory. A time step of $0.1 \mathrm{fs}$, a fictitious mass of $0.1 \mathrm{amu}$, and a maximum simulation time $200 \mathrm{fs}$ at $10 \mathrm{~K}$ were employed.

The ADMP trajectory for the $\mathrm{OH}$ anion on $\mathrm{I}_{\mathrm{h}}$ suggested that a proton abstraction from a water molecule on ice is very fast. Moreover, Fig.3(a) shows the behavior of $\mathrm{OH}^{-}$initially located on the surface. The progress of $\mathrm{O}(1)-\mathrm{H}(\mathrm{A})$ and $\mathrm{O}(5)-\mathrm{H}(\mathrm{A})$ distances during the initial proton abstraction from $\mathrm{O}(1)$ to $\mathrm{O}(5)$ can be seen in Fig. 3 (b). Around 20-40 fs, the proton stays between $\mathrm{O}(1)$ and $\mathrm{O}(5)$. After $40 \mathrm{fs}, \mathrm{O}(1)-\mathrm{H}(\mathrm{A})$ distance becomes large, indicating the termination of the first PHT process. Then, the second PHT is occurred from $\mathrm{O}(2)$ to $\mathrm{O}(1)$ at around $80 \mathrm{fs}$ (Fig. 3(c)). After that, we have observed a concerted PHT process from $\mathrm{O}(3)$ to $\mathrm{O}(2)$ and $\mathrm{O}(4)$ to $\mathrm{O}(3)$ at 110-130 fs (Figs 3(d) and (e)).

Starting from the snap shots of the ADMP trajectory, we have optimized stationary points for the PHT reaction path, and created a potential energy profile for ice $\mathrm{I}_{\mathrm{h}}$ (Fig. 4(a)). The calculated potential energy surface indicates that sequential PHT processes towards bulk ice are energetically favorable. At the starting point (SP) of the potential energy surface, the $\mathrm{OH}^{-}$on the surface is unstable, and connects to the local minima (LM1) at $51.9 \mathrm{kcal} / \mathrm{mol}$ below the $\mathrm{SP}$ without a barrier, where $\mathrm{OH}^{-}$is still located in the same layer. During the $\mathrm{SP} \rightarrow \mathrm{LM} 1$ transformation, the $\mathrm{OH}^{-}$ion on ice abstracts a proton from a $\mathrm{H}_{2} \mathrm{O}$ molecule neighboring on the surface. The structure of LM1 can transform into LM2 with a very low barrier (TS1) of $0.04 \mathrm{kcal} / \mathrm{mol}$. In LM2, the oxygen atom of the $\mathrm{OH}^{-}$ion interacts with hydrogen atoms of water molecules in the second layer, leading to an LM3 structure through a barrier of $0.6 \mathrm{kcal} / \mathrm{mol}$ (TS2). We found that the $\mathrm{OH}^{-}$ion at the $\mathrm{O}(3)$ position is unstable and undergoes PHT towards the $\mathrm{O}(4)$ position immediately, where a concerted motion of two hydrogen atoms is observed. Once the $\mathrm{OH}^{-}$ion migrates deeper below the second layer, we suspect that the 
barriers for the lowest energy PHT path are comparable to or less than the barriers we calculated. As a result, $\mathrm{OH}^{-}$ions can move inside the bulk through PHT that present almost no barrier.

In the case of amorphous ice, the potential energy surface for an $\mathrm{OH}^{-}$on amorphous ice is shown in Fig. 4(b) and computed ADMP trajectory is shown in Fig. 5. Consistent with the $\mathrm{I}_{\mathrm{h}}$ case, initial PHT process is occurred very quickly without a barrier during the SP $\rightarrow$ LM1 transformation. The second PHT has a barrier of $0.17 \mathrm{kcal} / \mathrm{mol}$, giving rise to LM2 $(-0.32 \mathrm{kcal} / \mathrm{mol})$. Then, the third PHT is occurred with a barrier of 0.73 $\mathrm{kcal} / \mathrm{mol}$, leading to LM3 $(-3.17 \mathrm{kcal} / \mathrm{mol})$. Overall, the PHT processes we calculated are almost barrierless, and are exothermic processes toward the bulk ice. Our amorphous ice model has a rather compact structure at the surface region. However, our experimental structures may contain cracks and defects that affect the PHT process. In order to gain quantitative insights about the structure-function relationship, running ADMP trajectories for long simulation time is required, which is out of the scope of present work.

Based on our ADMP and ONIOM calculations, we concluded that $\mathrm{OH}^{-}$on ice is unstable, and is immediately react with ice. Moreover, the initial PHT and the subsequent PHT processes are almost barrierless and exothermic, driving the $\mathrm{OH}^{-}$ towards ice bulk. The PHT mechanism in ice involves both single hydrogen atom or concerted motion of two hydrogen atoms, giving rise to efficient negative current. As the PHT processes are almost barrierless, quantum tunneling does not play a major role on the rate of the PHT in ice. This is consistent with our experimental observations as described in the next section, where the negative current is temperature independent and we did not observe kinetic isotope effects. Our ADMP calculations suggested that the almost barrier less PHT in ice occurs very quickly. Therefore, PHT is much faster than the thermal fluctuations of the hydrogen atoms in the hydrogen bond network of ice at very low temperature. As a result, hyper coordinate complex of $\mathrm{OH}^{-}$would not be formed, and this is in contrast to the liquid phase.

As recently reported in the literature, relatively less accurate computational method may lead to controversial conclusions among previous works for $\mathrm{OH}^{-}$transport in aqueous media through the PHT [12]. Therefore, we have used the wB97XD density functional for ADMP or two-layer ONIOM calculations, and domain-based local pair natural orbital couple (DLPNO)-CCSD(T) methods for calculating the potential energy surfaces for the PHT in ice. Also, relatively large ice clusters were used for modeling the PHT process. Both state-of-the-art computational methods and relatively large 
computational models would achieve reliable computed mechanism and reaction barriers for the PHT.

\section{Temperature and isotope dependences}

We performed the third experiment to further support our hypothesis in which the production of $\mathrm{OH}^{-}$ions on the surface triggers the PHT phenomena. If this process is indeed what occurs, then the negative current should appear while $\mathrm{OH}$ radicals exist on the surface, even after turning the UV off. In fact, the current gradually decreases after the UV light is off, as shown in Fig. 1(d). This depletion curve probably reflects the consumption of surface $\mathrm{OH}$ radicals remaining after UV termination. It should be noted that in Fig. 1(a), the current sharply responds to UV light because the electron and UV supplies are operated simultaneously. We first exposed ice to UV only for a given period and subsequently exposed it to electrons for 3 min soon after UV termination. As shown in Fig. 5(a), the current profiles are consistent with those obtained after UV termination in Fig. 1(d). The peak current gradually increases with increasing UV duration, reflecting the increase in the density of $\mathrm{OH}$ radicals on the surface. In Fig. 6(a), it is confirmed that no negative current appears during UV irradiation alone, although a slight positive current was observed due to photoelectron emission from the Ni substrate shown in Fig 6(b). The current depletion curves in Fig. 6(a) should result from the decrease in the amount of surface $\mathrm{OH}$ radicals due to the process of electron capture producing $\mathrm{OH}^{-}$ions and subsequently causing proton abstraction from the neighboring surface $\mathrm{H}_{2} \mathrm{O}$ molecule by $\mathrm{OH}^{-}$, thus controlling the negative current conductivity. The depletion curves for each UV duration can be well fitted by a single exponential function, $\mathrm{I}=\mathrm{I}_{0} \exp (-K t)$. That is, the depletion rate would be dominated by ate-limiting process of either electron capture or proton abstraction by $\mathrm{OH}^{-}$. An Arrhenius plot of $K$ is presented in Fig. 7. The temperature independence and the absence of an isotope effect in the experiment using heavy water ice indicate the very low barrier process rather than tunneling. Although the process causing the negative current is indicated to be barrier-less, the constant current was reduced with increasing amorphous ice thickness as mentioned in section 2. This thickness dependence can be explained qualitatively as follows. As described above, the negative current is suppressed by the photoelectron emission from the Ni surface. Such electrons can stored in the vicinity of ice-metal interface and further suppress the PHT. The thicker ice may store more number of electrons. In addition, the delivery of proton hole would be lost at the pores 
and cracks in amorphous ice. As a result, the negative current by the PHT may decrease in the thicker ice having more pores and cracks.

Finally, we roughly evaluate the consistency of the measured constant current in Fig. 1(a) with our scenario. Assuming that $\mathrm{OH}^{-}$ions are readily produced from $\mathrm{OH}$ radicals, that is, production rates of $\mathrm{OH}^{-}$and $\mathrm{OH}$ are equivalent, the current in terms of the number of electrons per second should be equivalent to the $\mathrm{OH}$ production rate at the surface by photodissociation of $\mathrm{H}_{2} \mathrm{O}$, which can be expressed by

$\frac{d\left[\mathrm{H}_{2} \mathrm{O}\right]}{d t}=f_{\mathrm{UV}} \sigma\left[\mathrm{H}_{2} \mathrm{O}\right] \sim 10^{-4}\left[\mathrm{H}_{2} \mathrm{O}\right]$,

where $f_{\mathrm{UV}}$ is the UV flux of $\sim 10^{13} \mathrm{~cm}^{-2} \mathrm{~s}^{-1}$ and $\sigma$ is the cross section for UV photodissociation of $\mathrm{H}_{2} \mathrm{O}$ in ice, $\sim 10^{17} \mathrm{~cm}^{2}$ [32]. Because the number of surface $\mathrm{H}_{2} \mathrm{O}$ molecules on the ice sample area of approximately $4 \mathrm{~cm}^{2}$ is on the order of $10^{15}$ particles, the production rate of $\mathrm{OH}^{-}$ions becomes $10^{11}$ particles $\mathrm{s}^{-1}$. This value is consistent with the observed current of $20 \mathrm{nA}$ corresponding to $\sim 10^{11}$ electrons.

We thank Drs. T. Hama, Y. Oba, G. Sazaki, K. Murata, Y. Furukawa (ILTS, Hokkaido University), and Y. Nakai (RIKEN) for their fruitful discussion. We also thank Mr. F. Saito at the Technical Division of ILTS for making the parts of experimental setup. We acknowledge for super computing resources at the Institute of Molecular Science in Japan. This work was partly supported by a JSPS Grant-in-Aid for Specially Promoted Research (JP17H06087).

[1] D. Marx, Proton Transfer 200 Years after von Grotthuss: Insights from Ab Initio Simulations. ChemPhysChem 7, 1848 - 1870 (2006).

[2] A. Y. Mulkidjanian, D. A. Cherepanov , J. Heberle, W. Junge, Proton Transfer Dynamics at Membrane/Water Interface and Mechanism of Biological Energy Conversion. Biochemistry (Moscow) 70, 251-256 (2005).

[3] K. Khistyaev et al., Proton Transfer in Nucleobases is Mediated by Water. J. Phys. Chem. A. 117, 6789-6797 (2013).

[4] D. Marx, M. E. Tuckerman, J. Hutter, M. Parrinello, The nature of the hydrated excess proton in water. Nature 497, 601-604 (1999). 
[5] X. Meng et al., Direct visualization of concerted proton tunneling in a water nanocluster. Nature Phys. 11, 235-239 (2015)

[6] E. Codourniu-Hernández, P. G. Kusalik, Probing the mechanisms of proton transfer in liquid water. Proc. Natl. Acad. Sci. USA 110, 13697-13698 (2013).

[7] J. P. Devlin, Relating the current science of ion-defect behaviour in ice to a plausible mechanism for directional charge transfer during ice particle collisions. Phys. Chem. Chem. Phys. 13, 19707-19713 (2011)

[8] J. P. Cowin, A. A. Tsekouras, M. J. Iedema, K. Wu, G. B. Ellison, Immobility of protons in ice from 30 to190 K. Nature 398, 404-407 (1999).

[9] N. N. Khusnatdinov, V. F. Petrenko, Experimental study of ice electrolysis under UV Irradiation. J. Phys. Chem. B 101, 6208-6211 (1997).

[10] A. I. Kolesnikov, G. Ehlers, E. Mamontov, A. Podlesnyak, Ice Ih revisited: No proton tunneling observed in a quasielastic neutron scattering experiment. Phys. Rev. B 98, 054301 (2018).

[11] E. Hückel, Theorie der Beweglichkeit des Wasserstoff- und Hydroxylions in wässeriger Lösung. Z. Electrochem 34, 546-566 (1928)

[12] M. Cheng et al., Hydroxide diffuses slower than hydronium in water because its solvated structure inhibits correlated proton transfer. Nature Chem. 10, 413-419 (2018).

[13] L. Cwikilk, J. P. Devlin, V. Buch, Hydroxide Impurity in Ice, J. Phys. Chem. A 113, 7482-7490 (2009).

[14] D. H. Lee, C. H. Choi, T. H. Choi, B. J. Sung, H. Kang, Asymmetric transport mechanisms of hydronium and hydroxide ions in amorphous solid water: hydroxide goes Brownian while hydronium hops. J. Phys. Chem. Lett. 5, 2568-2572 (2014).

[15] M. E. Tuckerman, D. Marx, M. Parrinello, The nature and transport mechanism of hydrated hydroxide ions in aqueous solution. Nature 417, 925-929 (2002).

[16] R. Sagi, M. Akerman, S. Ramakrishnan, M. Asscher, Temperature effect on transport, charging, and binding of low-energy electrons interacting with amorphous solid water films. J. Phys. Chem. C 122, 9985-9996 (2018).

[17] B. T. Draine, Physics of the Interstellar and Intergalactic Medium Ch.14 (Princeton University Press, Oxford, 2010) 
[18] V.F. Petrenko, N. N. Khusnatdinov, On the nature of photo charge carriers in ice. $J$. Chem. Phys. 100, 9096-9105 (1994).

[19] T. G. Slanger, B. Graham, Photodissociative channels at $1216 \AA$ for $\mathrm{H}_{2} \mathrm{O}, \mathrm{NH}_{3}$, and $\mathrm{CH}_{4}$. J. Chem. Phys. 77, 2432-2437 (1982).

[20] NIST database, https://cccbdb.nist.gov/elecaff1.asp

[21] Y. Horowitz, M. Asscher, Low energy charged particles interacting with amorphous solid water layers. J. Chem. Phys. 136, 134701 (2012).

[22] L. W. Chung et al., The ONIOM Method and its Applications. Chem. Rev. 115, 5678-5796 (2015).

[23]W. M. C. Sameera, F. Maseras, Expanding the Range of Force Fields Available for ONIOM Calculations: the SICTWO Interface. J. Chem. Info. Model. 58, 1828-1835 (2018).

[24] Gaussian 16, Revision A.03, M. J. Frisch et al. Gaussian, Inc., Wallingford CT, 2016.

[25]J.-D. Chai, M. Head-Gordon, Long-range corrected hybrid density functionals with damped atom-atom dispersion corrections. Phys. Chem. Chem. Phys. 10, 6615-6620 (2008).

[26]F. Weigend, R. Ahlrichs, Balanced basis sets of split valence, triple zeta valence and quadruple zeta valence quality for $\mathrm{H}$ to Rn: Design and assessment of accuracy, Phys. Chem. Chem. Phys. 7, 3297-305 (2005).

[27] W. D. Cornell, A second generation force-field for the simulation of proteins, nucleic-acids, and organic-molecules, J. Am. Chem. Soc. 117, 5179-5197 (1995).

[28] F. Neese, The ORCA Program System. WIREs Comput. Mol. Sci. 2, 73-78 (2012).

[29] S. Andersson, A. Al-Halabi, G-J. Kroes, E. F. van Dishoeck, Molecular-dynamics study of photodissociation of water in crystalline and amorphous ices, J. Chem. Phys. 124,064715 (2006)

[30] S. S. Iyengar, H. B. Schlegel, J. M. Millam, G. A. Voth, G. E. Scuseria, M. J. Frisch, $\mathrm{Ab}$ initio molecular dynamics: Propagating the density matrix with Gaussian orbitals. II. Generalizations based on mass-weighting, idempotency, energy conservation and choice of initial conditions. J. Chem. Phys. 115, 10291-302 (2001).

[31] R. Ditchfield, W. J. Hehre, J. A. Pople, Self-Consistent Molecular Orbital Methods. 9. Extended Gaussian-type basis for molecular-orbital studies of organic molecules, J. Chem. Phys. 54, 724-728 (1971). 
[32]N. Watanabe, T. Horii, A. Kouchi, Measurements of $\mathrm{D}_{2}$ yields from amorphous $\mathrm{D}_{2} \mathrm{O}$ ice by ultraviolet irradiation at $12 \mathrm{~K}$. Asrtophys. J. 541, 772-778 (2000). 
(a) $2.5 \times 10^{13} \mathrm{~cm}^{-2} \mathrm{~s}^{-1}$
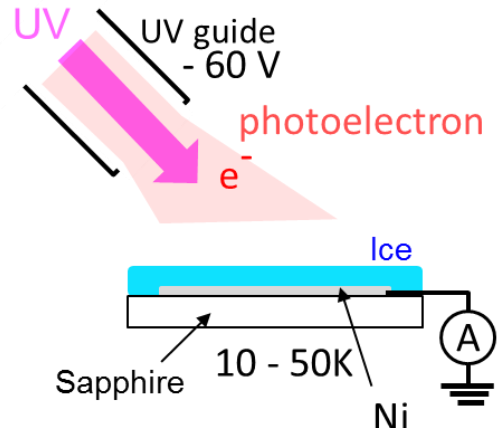

$\mathrm{Ni}$

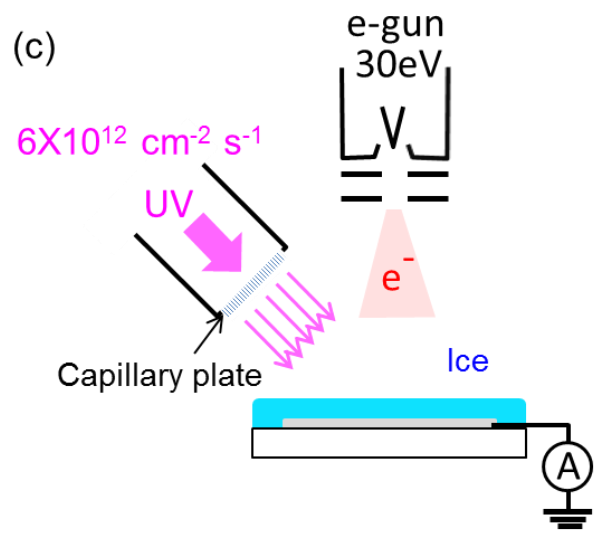

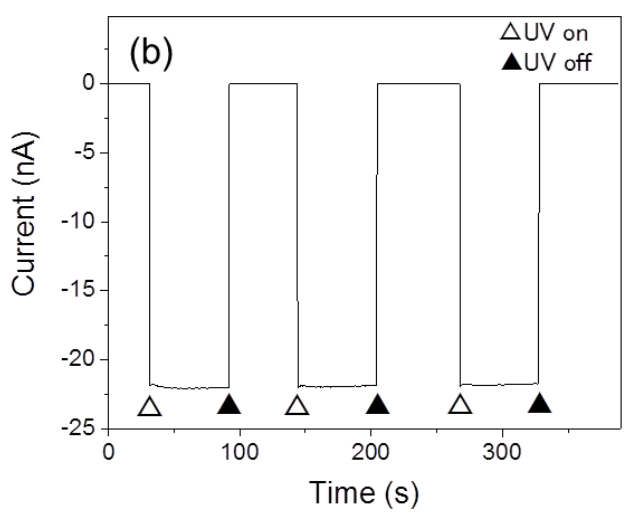

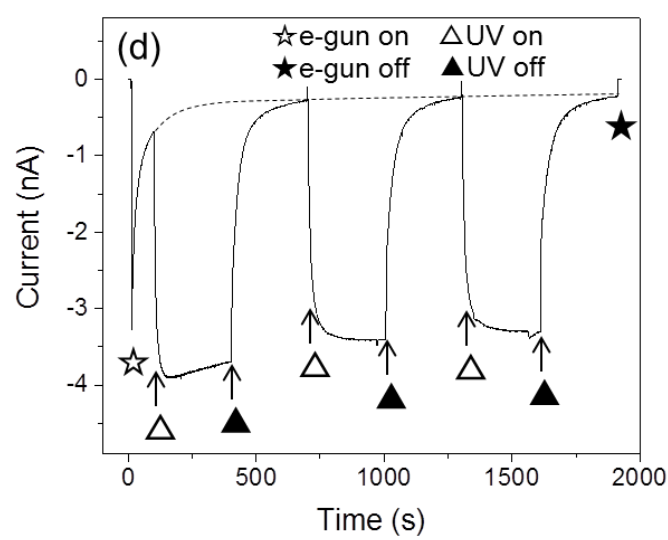

Fig. 1. The first experiment: (a) Diagram of the experimental setup; (b) Temporal variation in current measured through the $40 \mathrm{MLs}$ of ice at $20 \mathrm{~K}$ in the sequence of UV on and off with a coincident supply of electrons from the UV guide. The second experiment: (c) Diagram of the second experimental setup. By installing the capillary plate on the guide, the UV flux decreases to 25\%. (d) Temporal variation in the negative current during the sequential UV irradiation of $40 \mathrm{MLs}$ of ice at $15 \mathrm{~K}$ with continuous operation of the electron gun. The dashed line is the current level only due to the electron gun without UV irradiation. 


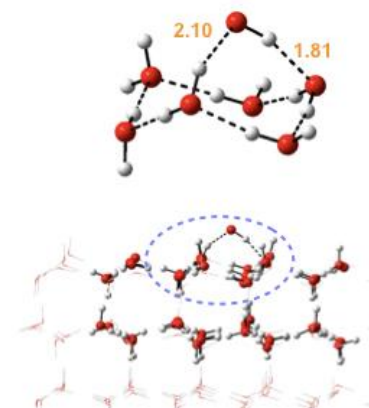

Side view

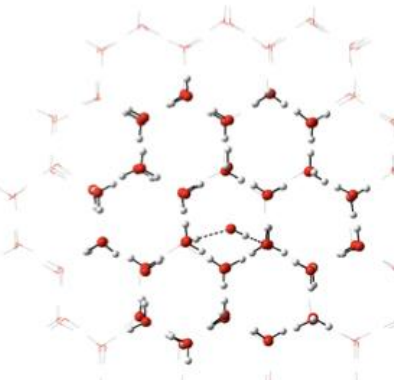

Top view

(a)

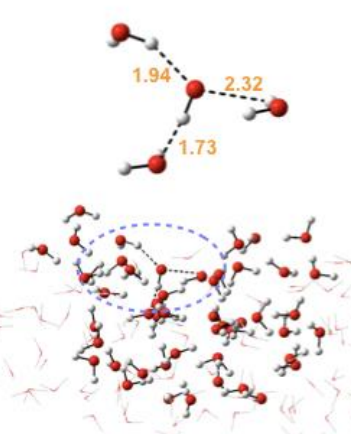

Side view

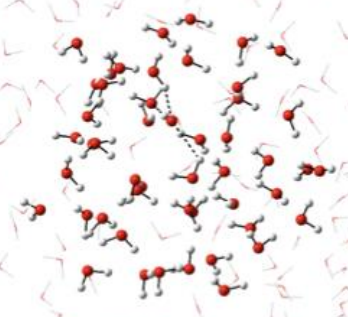

Top view

(b)

Fig. 2. Top and side views of the $\mathrm{QM} / \mathrm{MM}$ ice cluster models with an $\mathrm{OH}$ radical for (a) hexagonal water ice $\mathrm{I}_{\mathrm{h}}$ and (b) amorphous ice ("ball and sticks" shows the QM region and "wireframe" displays the MM region). Bond lengths are in $\AA$. 
(a)
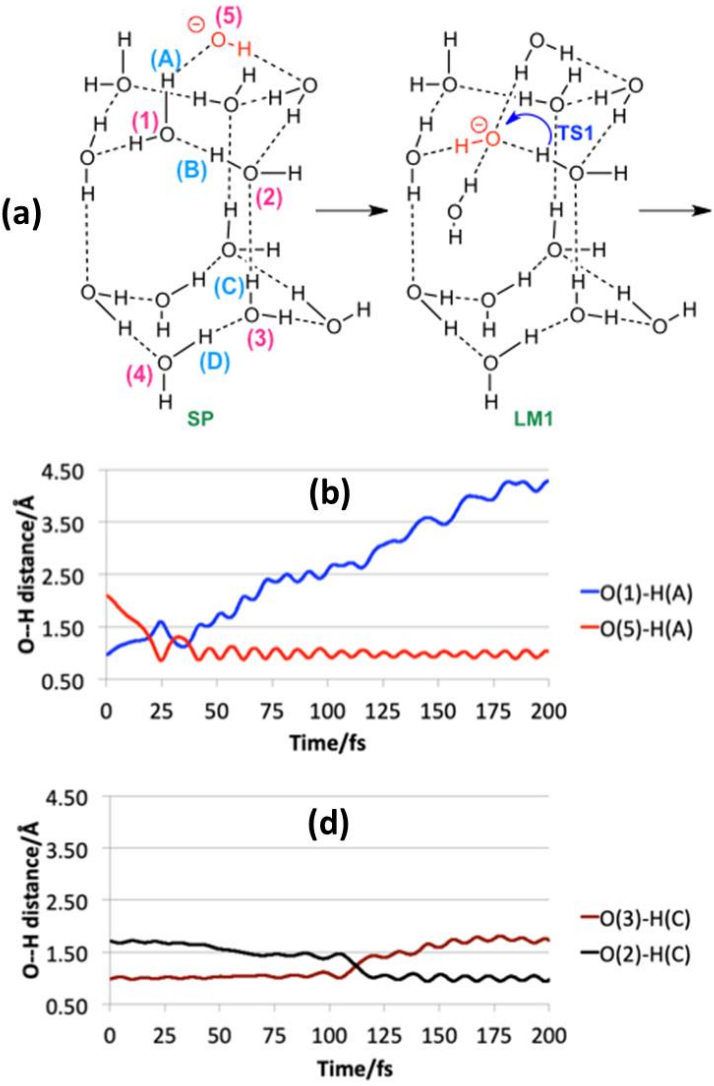
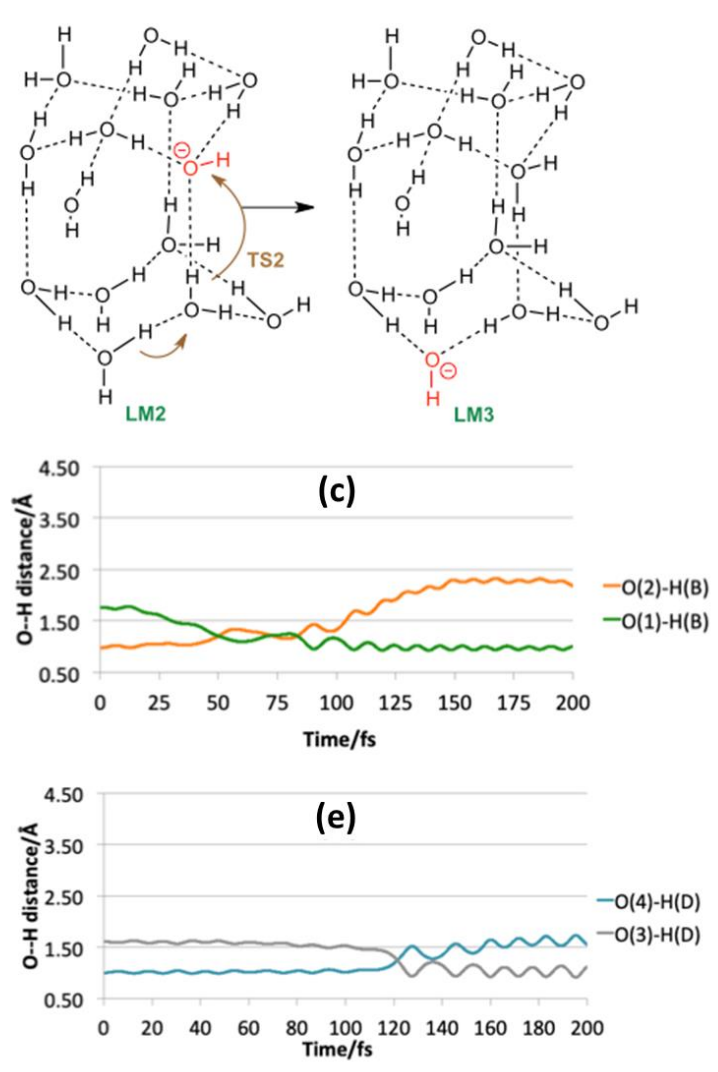

Fig. 3. The ADMP trajectory for the initial proton abstraction process on crystalline hexagonal ice $\left(I_{h}\right)$ calculated using the wB97X-D/6-31G(d) level of theory. (a) Schematic diagram showing the $\mathrm{OH}^{-}$migration path. (b) Progress of $\mathrm{O}(1)-\mathrm{H}(\mathrm{A})$ and $\mathrm{O}(5)-\mathrm{H}(\mathrm{A})$ distances. (c) Progress of $\mathrm{O}(2)-\mathrm{H}(\mathrm{B})$ and $\mathrm{O}(1)-\mathrm{H}(\mathrm{B})$ distances. (d) Progress of $\mathrm{O}(3)-\mathrm{H}(\mathrm{C})$ and $\mathrm{O}(2)-\mathrm{H}(\mathrm{C})$ distances. (e) Progress of $\mathrm{O}(4)-\mathrm{H}(\mathrm{D})$ and $\mathrm{O}(3)-\mathrm{H}(\mathrm{D})$ distances. 

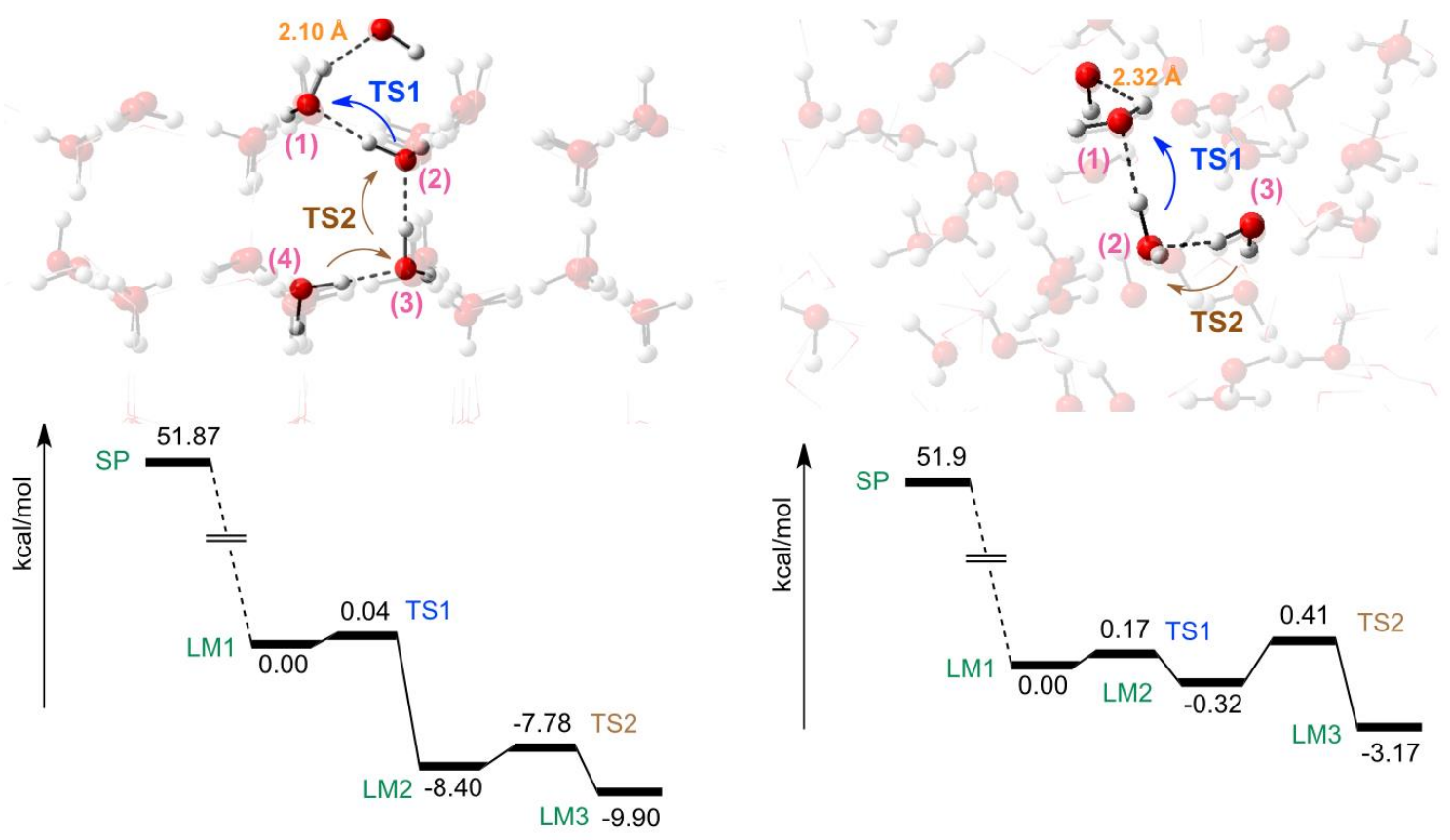

(a)

(b)

Fig. 4. Potential energy surface for the initial PHT processes on (a) crystalline ice $\left(\mathrm{I}_{\mathrm{h}}\right)$ and (b) amorphous ice calculated from the ONIOM method. LM1 is used as the reference energy point of the potential energy surface. 

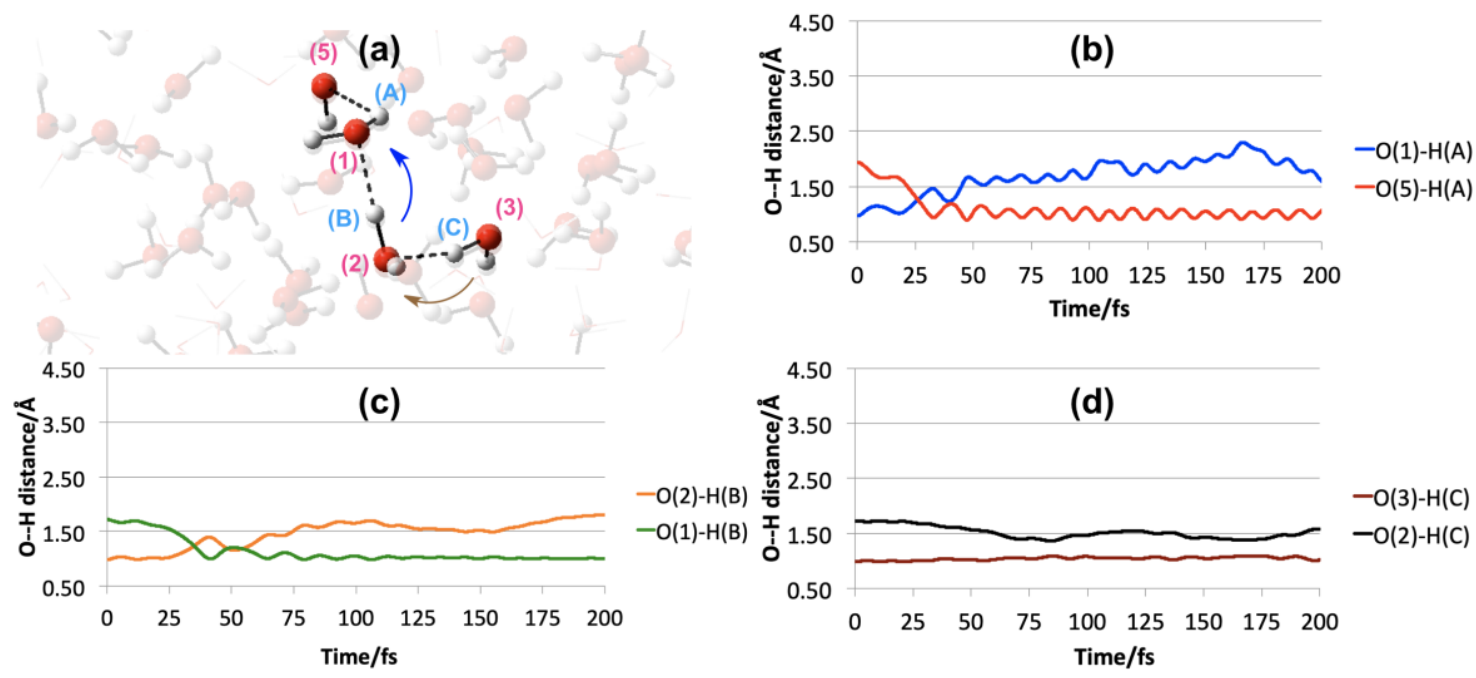

Fig. 5 The ADMP trajectory for the initial proton abstraction process on amorphous ice calculated using the wB97X-D/6-31G(d) level of theory. (a) Schematic diagram showing the $\mathrm{OH}^{-}$migration path. (b) Progress of $\mathrm{O}(1)-\mathrm{H}(\mathrm{A})$ and $\mathrm{O}(5)-\mathrm{H}(\mathrm{A})$ distances. (c) Progress of $\mathrm{O}(2)-\mathrm{H}(\mathrm{B})$ and $\mathrm{O}(1)-\mathrm{H}(\mathrm{B})$ distances. (d) Progress of $\mathrm{O}(3)-\mathrm{H}(\mathrm{C})$ and $\mathrm{O}(2)-\mathrm{H}(\mathrm{C})$ distances. 

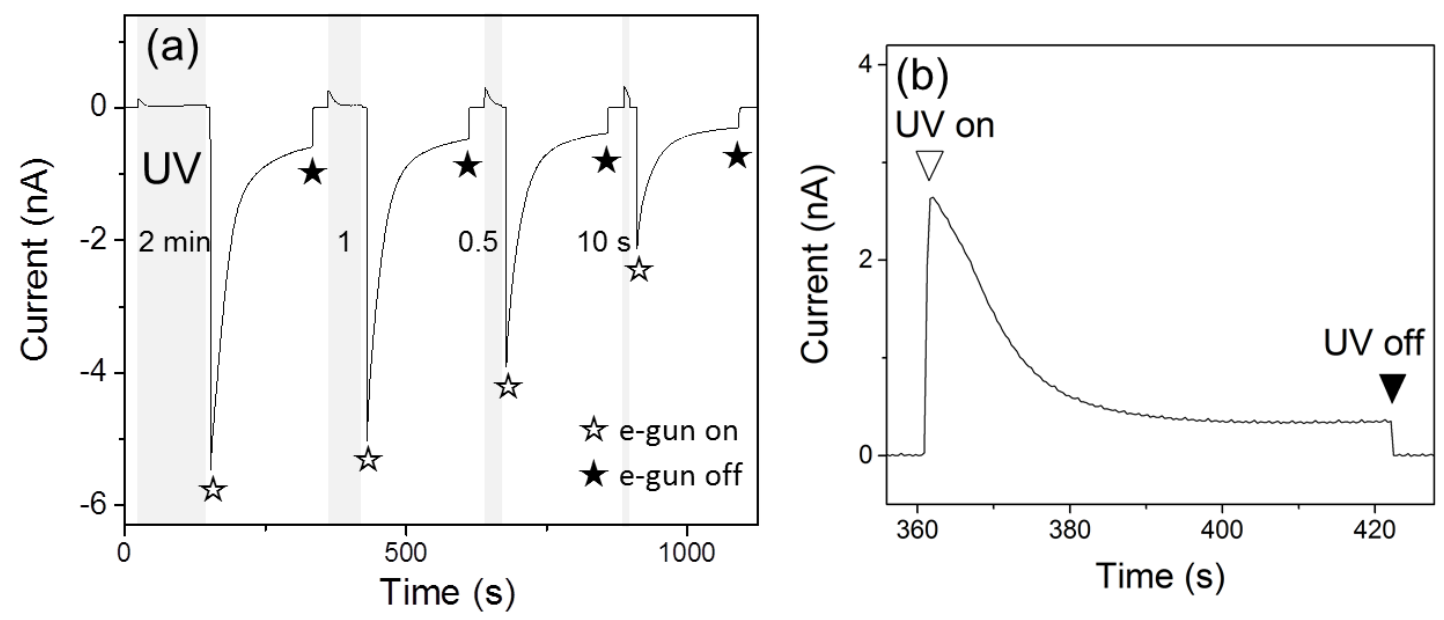

Fig. 6. The third experiment: (a) Temporal variation in current through the 40 MLs of ice at $15 \mathrm{~K}$. Sequence of UV irradiation of $2 \mathrm{~min}, 1 \mathrm{~min}, 0.5 \mathrm{~min}$ and $10 \mathrm{~s}$ followed by electron exposures for $3 \mathrm{~min}$ and (b) Enlarged view for 1-min UV irradiation only in Fig.6 (a). 


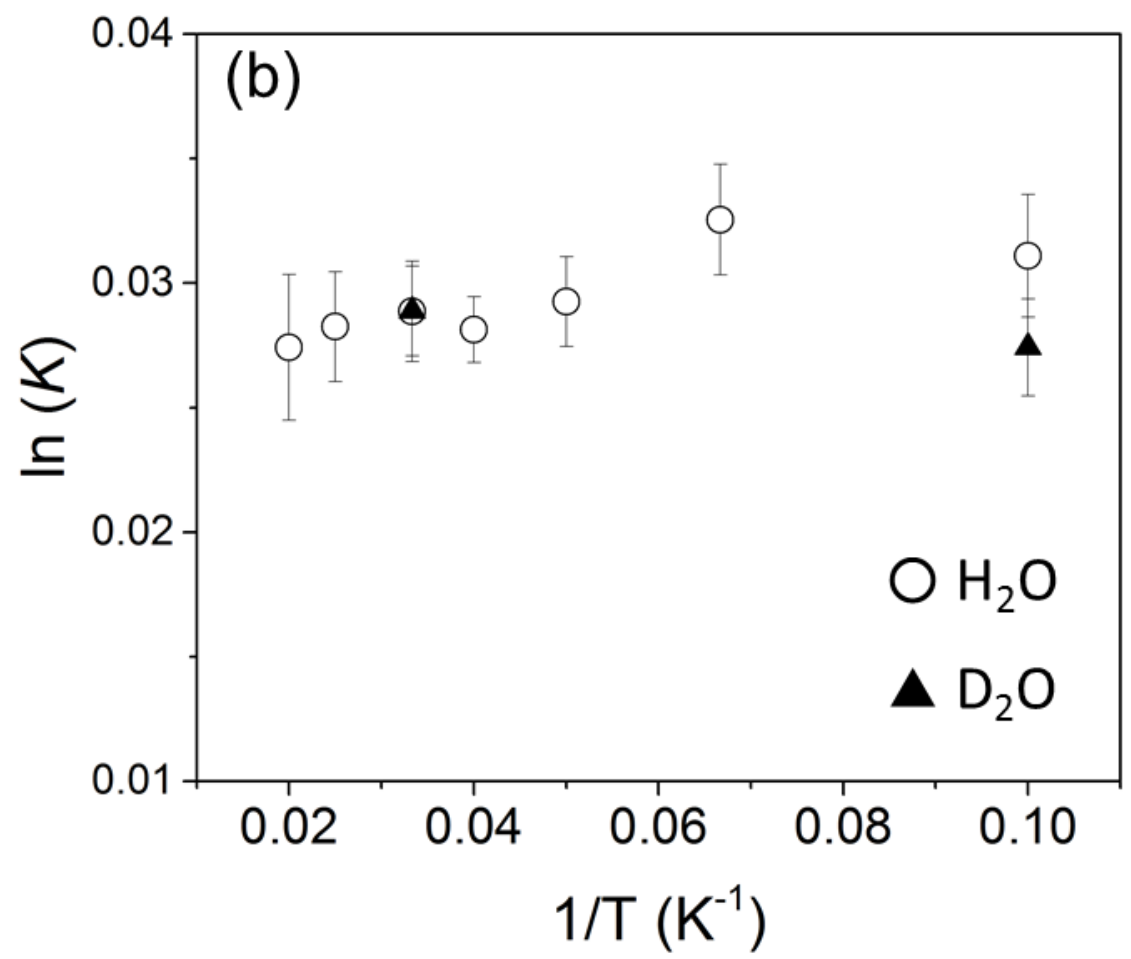

Fig. 7. Arrhenius plot of the negative current depletion rates obtained from fitting depletion curves (see Fig. 6(a)) to a single exponential. 